\title{
Hepatic Infection, CTCAE
}

National Cancer Institute

\section{Source}

National Cancer Institute. Hepatic Infection, CT CAE. NCI Thesaurus. Code C143541.

A disorder characterized by an infectious process involving the liver. 